\title{
Espaços liminares - natureza e função do limiar na paisagem contemporânea
}

\author{
Nature and Meaning of the Threshold \\ in the Contemporary Landscape \\ Espacios liminales - naturaleza y función del umbral \\ en el paisaje contemporáneo
}

Olivier Schefer (Université Paris 1 - Panthéon-Sorbonne, França)*

Tradução: Pedro Hussak (Universidade Federal Rural do Rio de Janeiro, Brasil) **

https://doi.org/10.22409/poiesis.v21i36.42735

RESUMO: O tema principal deste artigo é o do limiar nas artes visuais, pintura, fotografia e vídeo, analisado através de um ponto de vista romântico e especulativo. Pretendemos destacar os significados românticos da pintura paisagística, por exemplo, sua estrutura reflexiva, especialmente o "limiar duplo" das Rückenfiguren [Figuras vistas pelas costas] de Caspar David Friedrich, conectadas ao espectador e à parte não visível do horizonte. Esse conceito é muito relevante em vários contemporâneos que tentam tornar visível o limite invisível que conecta o tempo e o espaço, o próximo e o distante, o presente e o passado. Este texto explora as obras de Simon Faithfull e Marylène Negro que redescobre o conceito deleuziano de "tempo cristal" em seus vídeos gráficos.

PALAVRAS-CHAVE: romantismo; paisagem; arte contemporânea; Simon Faithfull; Marylène Negro

\footnotetext{
* Olivier Schefer é Professor da Université Paris 1 - Panthéon-Sorbonne, França. E-mail: olivierschefer@free.fr.

** Pedro Hussak é Professor Associado de Estética na Universidade Federal Rural do Rio de Janeiro (UFRRJ). E-mail: phussak@gmail.com. Orcid: https://orcid.org/0000-0002-4907-9093
} 
ABSTRACT: The main topic of this article is that of the threshold in visual arts, painting, photography and video, analysed through a romantic and speculative point of view. We intend to highlight the romantic meanings of the landscape painting, e.g. their reflexive structure, especially the "double threshold" of Caspar David Friedrich's Rückenfiguren [Figures seen from Behind], both connected to the viewer and to the non-visible part of the horizon. This concept is very relevant in several contemporaries' attempts to make visible the invisible boundary that connects time and space, the close and the distant, the present and the past. This text explores the works of Simon Faithfull and Marylène Negro who rediscovers the deleuzian concept of "time cristal" within her graphic videos.

KEYWORDS: romantism; landscape; contemporary art; Simon Faithfull; Marylène Negro

RESUMEN: El tema principal de este artículo es el umbral en artes visuales, pintura, fotografía y video, analizados desde un punto de vista romántico y especulativo. Tenemos la intención de resaltar los significados románticos de la pintura de paisajes, por ejemplo, su estructura reflectante, especialmente el "doble umbral" de Rückenfiguren [Figuras vistas desde atrás] de Caspar David Friedrich, conectadas al espectador y a la parte invisible del horizonte. Este concepto es muy relevante en muchos contemporáneos que intentan hacer visible el límite invisible que conecta el tiempo y el espacio, lo cercano y lo distante, el presente y el pasado. Este texto explora las obras de Simon Faithfull y Marylène Negro que redescubre el concepto deleuziano de "tempo cristal" en sus videos gráficos.

PALABRAS CLAVE: romanticismo; paisaje; arte contemporáneo; Simon Faithfull; Marylène Negro

Citação recomendada:

SCHEFER, Olivier. Espaços liminares - natureza e função do limiar na paisagem contemporânea. Revista Poiésis, Niterói, v. 21, n. 36, p. 67-82, jul./dez. 2020.

[https://doi.org/10.22409/poiesis.v21i36.42735]

(cc) BY-NC-ND

Este documento é distribuído nos termos da licença Creative Commons Atribuição-NãoComercial 4.0 Internacional (CC-BY-NC) (C) 2020 Olivier Schefer

Olivier Schefer, Espaços liminares - natureza e função do limiar na paisagem contemporânea. 


\section{Espaços liminares - natureza e função do limiar na paisagem contemporânea}

Limiar: fronteira do espaço e do tempo

Muitas vezes, experimentei um sentimento de

inquietação em encruzilhadas. Parece-me nesses momentos que nesses lugares ou quase que ali, a dois passos da via que eu não tomei e do qual já me afasto, sim, é ali que se abriria um país com uma natureza mais elevada onde eu teria podido viver e que doravante perdi. Entretanto, nada indicaria nem ao menos sugeriria, no momento da escolha, que seria necessário seguir esta outra estrada. (BONNEFOY, 2003, p. 7)

\begin{abstract}
Essas palavras de Yves Bonnefoy na abertura de sua mediação sobre o "Outro país" designam a promessa de um outro lugar no fundo da paisagem (como as paisagens em miniatura na pintura italiana da Renascença), de uma utopia escondida no visível: o que ele descreve de forma magnífica, como uma inquietação que o arranca da felicidade imediata e joga-o em uma errância sem fim, guarda justamente a ambiguidade da noção de limiar. O limiar da paisagem, que vai interessar-me aqui,
\end{abstract}


é ao mesmo tempo constitutivo do que chamamos paisagem, conquanto a consideremos em termos de representação, de quadro, de perspectiva, de ponto de vista e, por outro lado, o espaço limítrofe que escapa ao controle, pois põe em relevo uma impossível atribuição. O limiar é uma fronteira no interior do visível e uma utopia. Podemos ver, pensar, construir uma paisagem (uma imagem, uma representação) sem passar pelo limiar, mas inversamente o limiar não é uma condição ausente do visível?

Então, o que é um limiar? Onde começa e onde termina o limiar, se ele está condenado a desaparecer em e diante ao que ele dá a ver? Bonnefoy coloca-nos no encalço dessas dificuldades, quando escreve que o limiar marca a fronteira, que de outra forma seria invisível, entre o aqui e o lá: dois valores do espaço (o próximo, o longínquo) que também são duas dimensões do tempo. "Desejamos outro lugar", ele escreve, "apenas onde o aqui se afirma". O que Marcel Duchamp dizia-nos em sua maneira cheia de humor compondo essa porta dupla, essa junção: 11 rue I'Arrey. Ele realizou e instalou em 1927 esta porta no apartamento do $V^{e}$ arrondis- sement onde vivia à época; ela fechava tanto o ateliê quanto o banheiro, ou podia permanecer aberta entre os dois cômodos. De tal maneira que, marcando o limiar indefinidamente, ela ficava aberta quando estava fechada e fechada quando estava aberta.

Para caminhar em algumas manifestações do limiar contemporâneo, e interrogar o que ele permite perceber e segundo quais modalidades, proponho concentrar-me em alguns exemplos sintomáticos. Gostaria de abrir essas reflexões pelo espaço limítrofe da pintura de paisagem romântica que, sem dúvida, possui um valor emblemático.

\section{Caspar David Friedrich e o "duplo limiar"}

A noção de limiar, ou seja, de um ponto de vista e de um ponto de passagem, é certamente constitutiva da ideia mesma de paisagem, ao menos no Ocidente. Outras tradições, por exemplo, orientais, ignoram essa divisão que supõe uma distinção e uma relação entre um sujeito e um objeto. O Changchui chinês, montanhas e águas, é, imediatamente, uma paisagem 


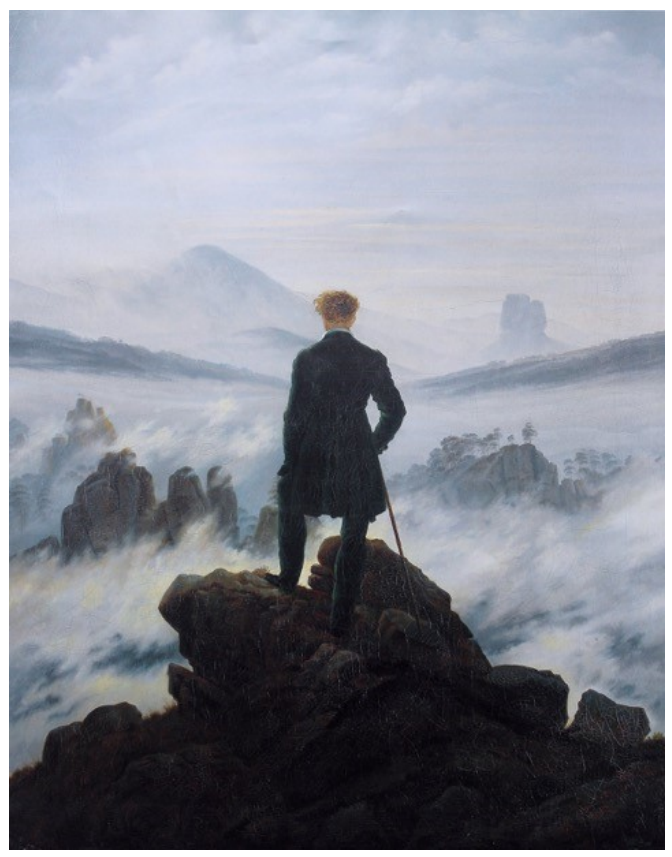

Fig. 1 - Caspar David Friedrich, Le Voyageur contemplant une mer de nuages, 1818.

$94,4 \times 74,8 \mathrm{~cm}$, Kunsthalle de Hambourg.

(Fonte: https://fr.wikipedia.org/wiki/Le_Voyageur_contemplant_une_mer_de_nuages)

Revista Poiésis, Niterói, v. 21, n. 36, p. 67-82, jul./dez. 2020. (https://doi.org/10.22409/poiesis.v21i36.42735) 
cosmogônica, sagrada em que jogam os elementos vitais (as figuras humanas aparecem ali neste todo natural, elas não o constroem). Por que tomar o momento romântico que não inventou o gênero pictural (seria antes Joachim Patinir) como ponto de partida? Caspar David Friedrich, em um conjunto de telas célebres, pinta justamente a paisagem e o contemplador que the está associado. A cada vez, aquele ou aquela ou aqueles estão em uma posição liminar. É possível ver em alguns exemplos: $O$ viajante contemplando um mar de nuvens (Fig. 1), Mulher diante do Iua. Diremos que Friedrich inverte de início o preceito de Aristóteles, aplicado na Renascença à pintura, de acordo com o qual "aqueles que imitam, imitam homens de ação". Na verdade, de ação, não há nada, nada se passa: simplesmente indivíduos de costas que miram, ao que parece, uma paisagem. Essa falta de ação, de mise-en-scène narrativa em conformidade com o gênero da pintura histórica, confere a essas telas uma dimensão evidentemente meditativa: em vez de agir, os personagens olham, contemplam; eles se encontram abismados tanto em si mesmos quanto no que eles veem. Esse é o precei-

to da pintura de paisagem de Friedrich e também desse romantismo pictural: a pintura de paisagem tem uma dimensão autorreflexiva e especular. Um dos teóricos do primeiro romantismo, August Wilhelm Schlegel, escreve significativamente na sua Doutrina da arte: "a paisagem enquanto tal não existe senão no olho daquele que a contempla". (apud RECHT, 1989 , p. 20) Representar uma paisagem nessa perspectiva romântica não é apenas pintar uma extensão natural, mas também e antes de mais nada pintar o olhar que a vê, que constrói uma extensão visível como paisagem. A autorreflexividade, a dimensão metavisual da paisagem romântica emerge com a emergência desse dispositivo recorrente em Friedrich, que consiste em pintar personagens de costas (Rückenfiguren) fazendo o que nós fazemos: olhar, contemplar diante de nós. Vemos uma paisagem através dos indivíduos que a olham. Notamos na paisagem que a maior parte das formas artísticas do primeiro romantismo tem uma dimensão intrinsecamente reflexiva: a arte interrogase, ao questionar o mundo e vice-versa. Fato que a eleva à altura de um símbolo de totalidade com cada fragmento da obra consciente de si. Toda poesia é poesia da 
poesia, diz Fr. Schlegel em 1798 (FR. SCHLEGEL, 2014, frag. 238) da mesma forma que a palavra "monológica", aquela que se ocupa apenas consigo mesma (e que renuncia a comunicar uma mensagem), para Novalis, é um símbolo da alma do mundo e da relação de seus objetos; ou ainda, um autor que quisesse escrever apenas um romance, diz o fragmento no 116 da revista Athenaeum, "apresentouse por acaso a si mesmo" (FR. SCHLEGEL, 2014, frag. 116). Schiller já notava que a diferença principal entre a poesia "ingênua" dos Gregos antigos e a "sentimental" dos modernos reside no fato de que os segundos colocam-se igualmente em cena em suas obras, ao passo que os primeiros apagam-se diante dela: Homero não está presente no que ele escreve, Cervantes, ao contrário, comenta as desventuras de seu herói, Don Quixote, e Jean Paul Richter torna-se mesmo um personagem das suas ficções. (SCHILLER, 2002)

Nesse dispositivo romântico reflexivo, nota-se facilmente que as figuras de costas ocupam o limiar: o limiar da tela, como objeto recortado e organizado, e o limiar da representação: eles têm um pé fora e um pé dentro. Essa posição liminar, dupla, mediadora autoriza justamente uma dupla leitura da paisagem romântica.

Apoiando-se em exemplos emprestados da literatura (Hypérion de Hölderlin) ou na Naturphilosophie de Schelling (síntese do subjetivo e do objetivo), seríamos inclinados a ver nessa maneira de reiterar as figuras pintadas, dispondo-as diante de uma paisagem, a expressão típica da empatia romântica, da fusão entre o eu e a natureza. Como conhecer alguma coisa que me é exterior e estranha, nota, por exemplo, Novalis em um de seus fragmentos teóricos, se eu não tenho já o seu germe em mim? Conhecimento por empatia, co-naissence, co-nascer, diria Paul Claudel (1907), conhecer não é mais julgar à distância, mas fazer um, nascer com o objeto; da mesma forma que o olho só pode ver o sol, estima Goethe depois de Plotino, se ele tornar-se solar (Sonnehaft).

Graças a esses poucos exemplos, podemos dizer que o romantismo se liberta do sistema de distanciamento que regulava a tese neoclássica. Essa é a tese do historiador francês Jean-Claude Lebensztejn, que escreve muito justamente: 
o neoclássico pensa as artes como um sistema de afastamentos: entre a arte e a natureza, e entre as diferentes artes, concebidas como idiomas imitativos. 0 romantismo inverte o ponto de vista, busca a fusão e 0 apagamento dos afastamentos; fusão entre artes, confusão dos gêneros, derramamento das artes na vida e da vida na arte. (LEBENSZTEJN, 1996, p. 57)

Mas, de outra maneira, o espaço do limiar e dos personagens de costas em Friedrich não assinalariam a impossível fusão, a distância, a diferença entre o eu e o todo natural? Tudo se desdobra nessa pintura no face-a-face angustiante, a confrontação melancólica entre o contemplador e o objeto longínquo ou reduzido a uma superfície artificial. Referindo-se às telas de Friedrich, Roland Recht nota justamente na Carta de Humboldt que os personagens pintados pelo pintor são citadinos (eles pertencem à História por seus trajes), deslocados diante de uma natureza que eles não podem mais capturar, senão pelo olhar. O que introduz uma curiosa tensão entre a referência contemporânea e um ambiente natural tornado mítico ou puro artifício. Esse intervalo diz, a seu modo, a distância dos sujeitos diante de uma natureza que eles contemplam à semelhança de um mito perdido ou como se olhassem uma simples imagem. "O homem não pode penetrar como ator na cena da História, ele é apenas, como a paisagem, o espectador resignado". (RECHT, 1989, p. 56)

\section{Depois de Friedrich: paisagem de costas}

Dentre os herdeiros conscientes ou não desse dispositivo liminar da paisagem de Friedrich, encontramos artistas que afirmam o retorno a uma grande natureza e, ao mesmo tempo, a distância, a nostalgia do país perdido. A fotógrafa Elina Brotherus fotografa-se de costas em um jogo de reflexividade romântica à segunda potência, diante das paisagens do Norte: precisa-se ver ali uma homenagem (muito?) apoiada no pintor, um desejo de fusão com elementos ou a imagem quase turística, um clichê da paisagem romântica; talvez tudo isso ao mesmo tempo? Em Simon Faithfull, a referência romântica é evidente, mas em parte inconsciente (se escutamos o artista): ele deixa-se fotografar de costas diante de um conjunto de paisagem com uma tee-shirt sobre a qual está escrito $0^{\circ}$. Isso designa a posição do Meridiano de Greenwich, essa linha de di- 
visão invisível, a referência internacional para o cálculo da longitude terrestre: ele segue essa longitude a partir do Norte (Groelândia) até a África, em Gana, depois do que, ela prossegue seu trajeto no oceano Antártico até o polo sul. Essa estranha deambulação paisagística é semirreal, semifictícia (a longitude é um marco invisível), em parte burlesca (vemos o artista em certos vídeos que documentam essa série, filmada de costas, seguindo, imperturbavelmente, seu GPS, transpondo tanto quanto possível todos os obstáculos: ele escala cercas, entra nas casas, atravessa um lago para seguir essa linha).

O artista não ocupa apenas um limiar na imagem, de costas, como também encarna literalmente a passagem e a linha fronteiriça, longitudinal. O limiar não é mais um ponto imaginário que permite entrar em uma paisagem. Ele se torna uma maneira de escrever a paisagem em movimento, de traçar nele seu eixo invisível, como fazia de outra maneira Dennis Oppenheim, materializando fusos horários com a ajuda de uma moto de neve que traça fronteiras do tempo no espaço.

\section{Marylène Negro: o limiar do visível e a geologia do tempo}

Gostaria agora de invocar mais longamente outra obra que concede um papel muito importante aos limiares e aos espaços de passagem na paisagem, aqui também através da imagem em movimento. Tratase da obra de uma artista contemporânea, Marylène Negro, que constrói sequências visuais a partir de imagens fotográficas. Ela não é diretora de filme no sentido clássico do termo (não há filmagem); o material de partida é a fotografia ou fotogramas de filmes recuperados e colocados em movimento. Essa colocação em movimento aparenta-se quase a uma sucessão de diapositivos.

Seu trabalho no computador permite a calibragem da luz e da sombra (jogos sobre a opacidade da imagem): seus filmes são, assim, acumulações de imagens, superposições de camadas cujo desenrolar desenvolve a densidade, a espessura.

Há duas intuições fortes nesse trabalho: (1) A primeira é o emprego de uma genealogia do visível: não se trata apenas de mostrar paisagens, objetos, corpos, rostos, 


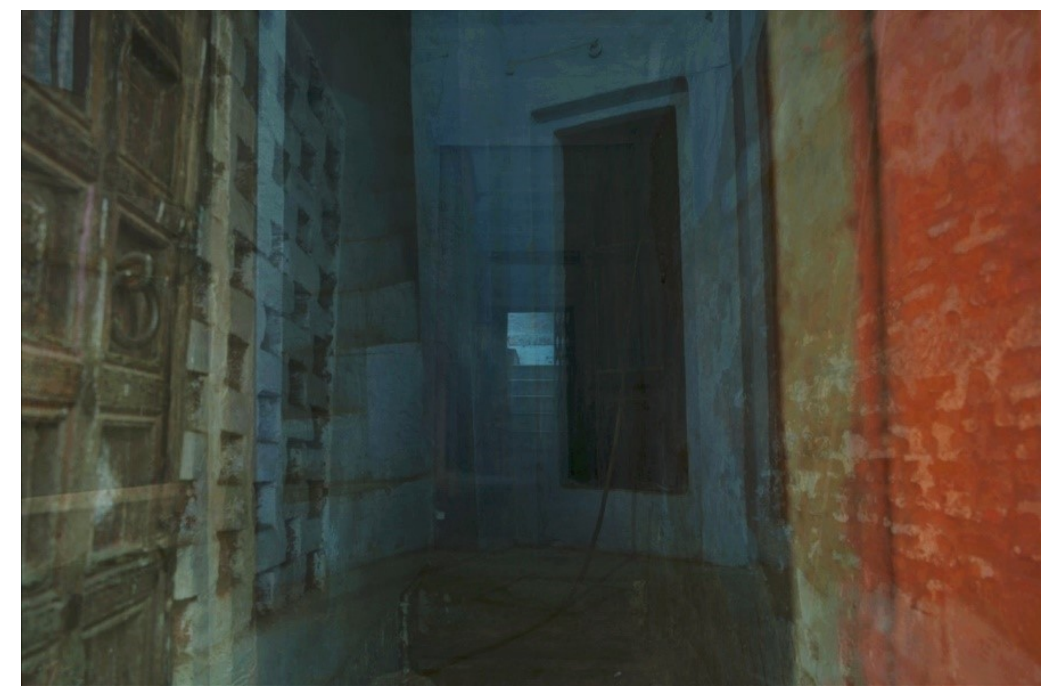

Fig. 2 - Marylène Negro, Pass, 2018.

23 min $13 \mathrm{~s}$ (vídeo-fotos)

(Fonte: Imaqens cedidas pela artista)

Olivier Schefer, Espaços liminares - natureza e função do limiar na paisagem contemporânea. 


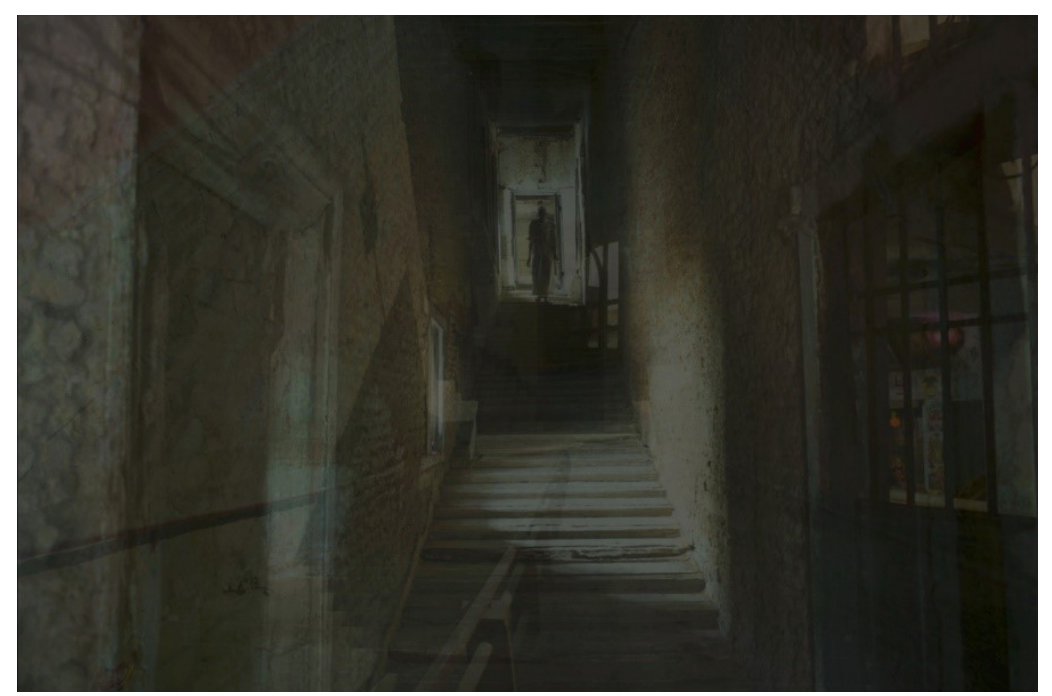

Fig. 3 - Marylène Negro, Pass, 2018.

$23 \mathrm{~min} 13 \mathrm{~s}$ (vídeo-fotos)

(Fonte: Imagens cedidas pela artista)

Revista Poiésis, Niterói, v. 21, n. 36, p. 67-82, jul./dez. 2020. (https://doi.org/10.22409/poiesis.v21i36.42735) 
mas de mostrar como eles aparecem progressivamente, ou inversamente, como eles desaparecem. Temos ali todo um processo foto-fílmico que instrui a chegada, a comparência das figuras, também sua qualidade de desintegração. Daí esse sentimento de estar na presença de uma revelação quase original, por momentos, cósmica, de manter-se diante de uma natureza que emerge. Essa genealogia do visível é uma genealogia das figuras: há sempre um dado inicial, imagem fixa, plano geral que é progressivamente modificado ou revelado. (2) A segunda intuição reside nesse advérbio "progressivamente": essa obra é assombrada pela lentidão. O tempo de elaboração, genealógico, é um tempo lento, inabitual, quase inumano e não o tempo subjetivo: é o que torna seus foto-filmes às vezes difíceis de olhar, pois seu tempo não nos diz respeito imediatamente. Ele escapa a nossos modos de percepção das imagens (um tempo vivido, experimentado, refletido e ligado a uma cinética, aos movimentos de nosso corpo). Aqui o tempo do filme escapa ao sujeito, ao sentido em que ele é fruto de uma superposição realizada de forma maquinal (o resultado, o encadeamento, as transformações das paisagens são assim, em grande parte, aleatórios: eles não dependem de uma decisão do artista). Podemos, em suma, falar de um tempo natural, geológico, de uma geologia dos elementos. Esse tempo lento, geológico, manifesta-se através da montagem de estratos, de superposições de imagens fixas.

Olhemos um extrato de Pass (Fig. 2 e Fig. 3). O filme dura vinte minutos: trata-se de um filme composto por fotografias tomadas na Índia, em Benares, restituídas por suas arquiteturas tortuosas, incertas, insolventes, labirínticas: acreditaríamos estar em uma gravura de Piranese sobre prisões subterrâneas. Uma paisagem subterrânea que nos faz avançar enquanto permanecemos no mesmo lugar, um tipo de viagem imóvel ao país do limiar. Limenland era, além disso, o título de um de seus filmes, uma sequência de Inland Empire de David Linch em um corredor, montado imagem por imagem, esvaziado de seus diálogos: não restava mais na sua versão senão um lento escoamento de cores.

Poderíamos olhar o trabalho desta artista com a ajuda de alguns elementos teóricos provenientes da tese deleuziana sobre a imagem-tempo. Eu lembro, em grandes linhas, 

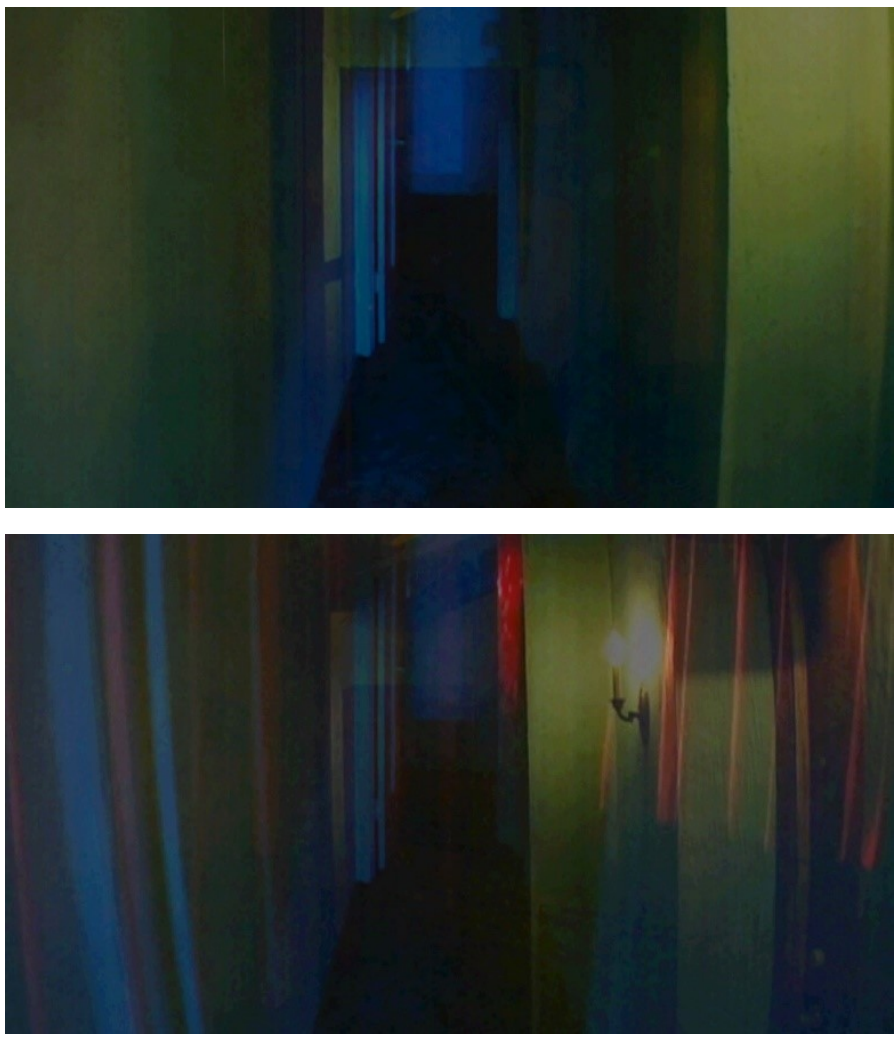

Fig. 4 e 5 - Marylène Negro, Limenland, 2015.

$20 \mathrm{~min} 15 \mathrm{~s}$ (vídeo-fotos)

(Fonte: imaqens cedidas pela artista)

Revista Poiésis, Niterói, v. 21, n. 36, p. 67-82, jul./dez. 2020. (https://doi.org/10.22409/poiesis.v21i36.42735) 
que Deleuze identifica no cerne do cinema, incialmente, um momento clássico: orgânico, aristotélico, marcado pela prioridade do mýthos, da fábula narrativa e pela coerência do todo (DELEUZE, 1985). O tempo da sucessão e aquele da narração estão ao serviço de uma narração, de uma ação. Ele identifica, como um pivô, uma "crise da imagem ação", que corresponde, grosso modo, ao nascimento de um segundo momento do cinema, aquele da sua modernidade que aparece no pós-Segunda Guerra Mundial: com Hitchcock, o sintomático, Janela indiscreta [Rear Window], cujo protagonista está reduzido a situações visuais e sonoras puras, enquanto o esquema da narração se decompõe. O herói (James Stewart) não age mais, mas ele contempla e monta através de sua teleobjetiva as cenas que vê, como voyeur; o real torna-se um painel de imagens e de representações.

Ele se mantém, como um personagem de Friedrich, constantemente sobre o limiar do visível: aqui e lá, sobre uma junção. A crise narrativa e o nascimento de um cinema perceptivo e memorial advêm também mais francamente com o Neorrealismo italiano e a Nouvelle Vague.
Essa crise da narração que possibilita a emergência de um cinema do tempo puro, como condição transcendental das imagens, desarruma o modelo narrativo da imagem-movimento. As histórias se decompõem, perdem sua importância, os heróis são tomados em suas errâncias sem metas, o cinema reflete o que ele é. O esquema sensório-motor (a serviço da história) é contrariado, o cinema moderno inventa o tempo puro, a intuição do tempo como experiência metafísica ou política (o cinema que se toma por objeto questiona sempre a economia e o dinheiro).

O que me interessa situa-se no capítulo 4 da Imagem-tempo ("os cristais de tempo"). Gilles Deleuze retoma a tese de Bergson sobre a duração pura, o tempo vivido. Esse tempo vivido é um tempo qualitativo e, sobretudo, homogêneo, ligado, sem corte, contrariamente às representações quantitativas e especializadas do tempo heterogêneo dos horloĝos e da numeração (DELEUZE, 1985, p. 92). O próprio desse tempo é que ele encadeia indistintamente presente-passado-futuro. Para Deleuze, depois de Bergson, o tempo não é sucessivo e diacrônico, como se um momento interviesse após um outro e que 
cada um expulsasse o anterior. O tempo é sincrônico e simultâneo: as hipóstases do tempo não ocorrem uma após a outra, mas conjuntamente, simultaneamente. O presente não se torna passado para em seguida transformar-se em futuro: o passado coexiste com o presente que ele foi. O tempo é uma fiação extremamente sutil, delicada, infrafina, entre suas dimensões diferentes. Elas ocorrem a cada momento juntamente e não separadamente.

Assim, Deleuze pensa o cinema moderno como a produção de imagens mútuas, no cerne das quais coexistem o atual (presente) e o virtual (passado-futuro), o real e o imaginário, a percepção e a lembrança. O tempo divide-se em cada um dos seus momentos, sem perder suas dimensões múltiplas. Há uma "coalescência" dos tempos no tempo. O presente torna-se passado ao mesmo tempo em que está presente (ele não se torna passado depois). Isso é uma imagem-cristal, uma imagem em espelho que mostra o original e seu duplo, seu reflexo, o presente e seu tornar-se passado. "O passado não sucede ao presente que ele não é mais, ele coexiste com o presente que ele foi".
Maylène Negro mostra esse regime mútuo e duplo da imagem, a indistinção dos tempos e das figuras. O que vemos efetivamente? (1) A lenta trama, a sucessão das imagens e, portanto, o escoamento mesmo dos tempos, ela agarra o momento em que o presente se cinde em passado e em que este superpõe-se - como a persistência retiniana, a imagem-fantasma à imagem atual. (2) Compreende-se então a predileção da artista por espaços de passagem e de limiar que dão justamente a ver, a agarrar esses tempos infrafinos, essas modificações do tempo: através das passagens, corredores, escadas, labirintos. Essas transformações, esses colapsos, declínios, desaparições, aparições são a trama do tempo solidário e coalescente (tempo-cristal, sincrônico de dimensões diferentes) e não o recorte arbitrário em partes distintas.

Deleuze escreve ainda: "O cristal na verdade não cessa de mudar as duas imagens distintas que o constituem, a imagem atual do presente que passa e a imagem virtual do passado que se conserva: distintas e, entretanto, indiscerníveis, e tanto mais indiscerníveis que distintas 
uma vez que não se sabe qual é uma e qual é a outra".

Em suma, poderíamos ver nos quadros móveis dos filmes lentos de Marylène $\mathrm{Ne}$ gro, o emprego de genealogias visíveis e de geologias de imagens: as paisagens atravessadas que desmoronam umas sobre as outras são todas paisagens temporais. Passagens que, modificando sem cessar, dão a ver a dimensão da dupla face do tempo, o cristal tempo e não seu fluxo irreal.

Marylène Negro constrói a paisagem em país longínquo e eu retorno, para terminar essas incursões nos limiares do visível do "interior do país", a esta interrogação primeira de Yves Bonnefoy: "É aqui que acaba o que eu deixo, é aqui que o outro mundo começa?"

\section{Referências}

BONNEFOY, Yves. L'arrière-pays. Paris: Gallimard, 2003.

CLAUDEL, Paul. Art poétique (Connaissance du temps - Traité de la connaissance au monde et de soi-même - Développement de l'Eglise). Paris: Mercure de France, 1907.

DELEUZE, Gilles. Image-Temps: cinéma 2. Paris: Minuit, 1985.

LEBENSZTEJN, Jean-Claude. De l'imitation dans les beaux arts. Paris: Hoebeke, coll. Arts \& Esthétique, 1996.

SCHLEGEL, Friedrich. Fragmente. Athenaeum. Eine Zeitschrift von August Wilhelm Schlegel und Friedrich Schlegel. Ersten Bandes Zweytes Stück, Berlin, 1798. Digitale Edition von Jochen A. Bär. München: Vechta, 2014.

SCHILLER, Friedrich. De la poésie naïve et sentimentale. Paris: Arche Éditions, 2002.

RECHT, Roland. La Lettre de Humboldt. Du jardin paysager au daguerréotype, Christian Bourgois, Paris: 1989. 